\title{
Anesthetic Implications of Emergent Cesarean Section in a Parturient with Marfan Syndrome Complicated by Ascending Aortic Aneurysm and Heart Failure
}

Young Sung Kim ${ }^{1}$, Byung Gun Lim ${ }^{1 *}$, So Hyun Lee ${ }^{1}$, Sang Hoon Park ${ }^{1}$, Woo Jun Jung ${ }^{1}$, Myoung Hoon Kong ${ }^{1}$, II Ok Lee ${ }^{1}$

1. Department of Anesthesiology and Pain Medicine, Korea University Guro Hospital, Korea University College of Medicine, Seoul, Korea

\begin{abstract}
Cardiovascular comorbidities to the Marfan syndrome may induce hemodynamic instability especially in the parturients during labor or delivery. For anesthesiologists, it is challenging to maintain hemodynamic stability during Cesarean section in those patients with Marfan syndrome. Remifentanil is an ultra-short-acting opioid with rapid onset and offset of action which provides cardiovascular stability during surgery. Together with remifentanil, the use of a laryngeal mask airway can reduce the risk of hypertensive response followed by tracheal intubation. We describe the successful administration of remifentanil and application of laryngeal mask airway for emergent Cesarean section performed under general anesthesia in a patient with Marfan syndrome complicated by ascending aortic aneurysm and heart failure. The use of remifentanil (loading dose of $1 \mu \mathrm{g} / \mathrm{kg}$ for $1 \mathrm{~min}, 2 \mathrm{~min}$ before induction; thereafter continuous infusion dose of $0.1 \mu \mathrm{g} / \mathrm{kg} / \mathrm{min}$ ) was useful to maintain hemodynamic stability of the parturient throughout the surgery without neonatal respiratory depression.
\end{abstract}

Keywords: Ascending Aortic Aneurysm; Cesarean section; Laryngeal mask airway; Marfan syndrome; Remifentanil

\section{Introduction}

Marfan syndrome is a connective tissue disorder that involves many organs such as skeletal, ocular, cardiovascular and pulmonary system (1). Especially for cardiovascular comorbidities such as aortic dilation and dissection, it is challenging to maintain hemodynamic stability during surgery in patients with Marfan syndrome (2). For women with Marfan syndrome, there is an increased risk of aortic dissection in the third trimester of pregnancy, labor and delivery, and the first postpartum month (3). For those patients, the key anesthetic management of

\section{Corresponding author:}

Byung Gun Lim, M.D., Ph.D.

Department of Anesthesiology and Pain Medicine, Korea University College of Medicine, Guro Hospital, 148

Gurodong-ro, Guro-gu, Seoul, Korea

Tel: +82-2-2626-1437 Fax: +82-2-851-9897 E-mail address: bglim9205@korea.ac.kr

Receive date: 2014-05-25 | Accept date: 2014-06-25 | Publish date:

2014-07-04 DOI: 10.7575/aiac.abcmed.14.02.02.16 
delivery is to prevent elevation of blood pressure (BP) using administration of opioids before delivery, or titrated antihypertensive administration (4).

Among the opioids, remifentanil is an ultrashort-acting opioid with rapid onset and offset of action. It blunts stress responses, and provides cardiovascular stability during surgery (5). Thus, remifentanil infusion may facilitate vaginal delivery during second stage labor in high-risk parturients (6). However, there is still a potential risk of neonatal depression when it is overdosed.

The insertion of laryngeal mask airway (LMA) instead of endotracheal tube can avoid the hypertensive response followed by tracheal intubation (7). Furthermore, the remifentanil infusion can improve the LMA insertion conditions associated with mouth opening, ease of insertion, coughing and gagging, and laryngospasm (8).

This report describes the successful anesthetic management using remifentanil and LMA for Cesarean section, performed under general anesthesia in a patient with Marfan syndrome complicated by ascending aortic aneurysm and heart failure.

\section{Case report}

A 31 year-old parturient woman (para 0 gravida 0 , weight $71 \mathrm{~kg}$, height $174 \mathrm{~cm}, 37+5$ weeks of gestation) was admitted to the hospital via emergency department. She complained of dyspnea on exertion and intermittent chest discomfort. On her physical examination, she had the arachnodactyly and a positive thumb sign. There was an early diastolic low pitched cardiac murmur on the chest auscultation. The electrocardiogram (ECG) revealed frequent premature ventricular contractions (PVCs) (24 times/min, ventricular rates of 98 beats $/ \mathrm{min}$ ).
Cardiomegaly (cardiothoracic ratio 70\%) could be observed on the chest radiograph. The 2Dechocardiography revealed severe aortic regurgitation (grade 4), mild mitral regurgitation (grade 1 ), markedly dilated sinus $(64.9 \mathrm{~mm})$, sino-tubular $(58.2 \mathrm{~mm})$ and tubular $(51.5 \mathrm{~mm})$ portion of ascending aorta, and enlarged left ventricle $(66.2 \mathrm{~mm})$. The ejection fraction was decreased to $45 \%$. Taken together, we strongly suspected Marfan syndrome with ascending aortic aneurysm and dilated cardiomyopathy. Two hours after her arrival, she complained of labor pain. Before long, uterine contractions occurred every 2-3 $\mathrm{min}$. The fasting time was $8 \mathrm{~h}$. Therefore, we had to make a plan for emergent delivery.

Glycopyrrolate $0.2 \mathrm{mg} \mathrm{IM}$ and oral ranitidine $150 \mathrm{mg}$ were premedicated $30 \mathrm{~min}$ before surgery. Two 18 gauge IV catheters were placed in both antecubital veins. When the patient arrived at the operating room (OR), she was monitored with an ECG, pulse oximetry, bispectral index (BIS) and noninvasive BP monitor. BP was monitored at 1 min intervals, and heart rate (HR) was monitored continuously. Before induction, adequate resuscitation facilities for neonate and mother were prepared. The initial vital signs were HR 85 beats/min, BP 165/65 $\mathrm{mmHg}$, body temperature $36.7{ }^{\circ} \mathrm{C}$ and pulse oximeter oxygen saturation $98 \%$. After denitrogenation with $028 \mathrm{~L} / \mathrm{min}$, remifentanil $1 \mu \mathrm{g} / \mathrm{kg}$ was given for $1 \mathrm{~min}$ as a loading dose 2 min before induction; thereafter continuous infusion dose of $0.1 \mu \mathrm{g} / \mathrm{kg} / \mathrm{min}$ was given. General anesthesia was induced by thiopental sodium $350 \mathrm{mg}$ and succinylcholine $70 \mathrm{mg}$ for rapid sequence induction. The cricoid pressure was applied during anesthetic induction. After muscle paralysis was achieved, a size 4.0 classic LMA was inserted and the successful placement was confirmed by auscultation and a capnogram. Anesthesia 
was maintained with remifentanil infusion in $023 \mathrm{~L} / \mathrm{min}$ until the newborn was out. Fetal expulsion was performed after 4 min from skin incision. The Apgar score of the neonate was 8 at $1 \mathrm{~min}$, and 10 at $5 \mathrm{~min}$. There was no neonatal depression. After fetal expulsion, 50 $\%$ nitrous oxide with midazolam $5 \mathrm{mg}$, fentanyl $300 \mu \mathrm{g}$, and vecuronium $4 \mathrm{mg}$ IV were given to the parturient. The infusion of remifentanil was maintained for $32 \mathrm{~min}$ after fetal expulsion. After the end of surgery, all anesthetics were stopped. Then, the selfrespiration was recovered in $74 \mathrm{~s}$, spontaneous eye opening was observed in $132 \mathrm{~s}$, and removal of LMA was done in $220 \mathrm{~s}$ (awake but calm without coughing). The patient was sent to an intensive care unit (ICU) with $025 \mathrm{~L} / \mathrm{min}$ via mask without any complications. The hemodynamics was stable throughout the surgery (Figure 1). There were no ST or T changes or PVCs on ECG monitoring during the surgery. The total operation time was $44 \mathrm{~min}$ and the total remifentanil dose was $337 \mu \mathrm{g}$. BIS value was kept within 40-70 throughout the surgery. An intravenous patient-controlled analgesia was initiated to the patient at the flow rate of $0.5 \mathrm{ml} / \mathrm{h}$ with a $45 \mathrm{ml}$ mixture containing sufentanil $250 \mu \mathrm{g}$, ketorolac $150 \mathrm{mg}$ and ramosetron $0.6 \mathrm{mg}$ for postoperative pain control before leaving the OR (A bolus dose: $0.5 \mathrm{ml}$, a lockout interval: $15 \mathrm{~min}$ ). Thereafter, she was stable without any hemodynamic or respiratory complications in the ICU. Pain score assessed by using a numerical rating scale ( $0=$ no pain, $10=$ maximum pain imaginable) was less than 4 in the ICU. Three days later, the ectopia lentis was diagnosed by an ophthalmologist, which confirmed the diagnosis as Marfan syndrome. Twenty-nine days later, the patient underwent the successful aortic root and mitral valve replacement. Her cardiac symptoms were improved and the newborn infant is growing well without any problems.

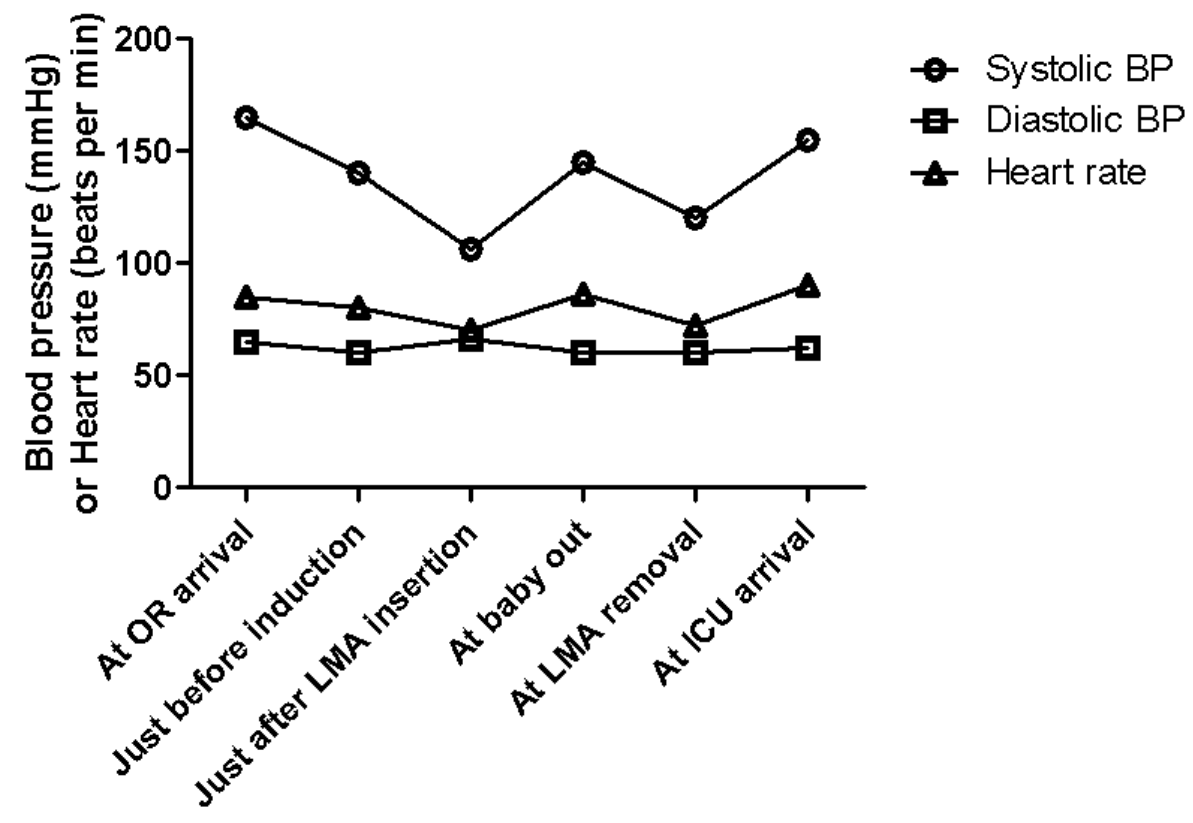

Figure 1: The perioperative hemodynamics of the patient. It is viewed in the time domain. The vertical axis is blood pressure or heart rate and the horizontal axis is time. The hemodynamics was stable during the operation when considering their initial values. OR: operating room. BP: blood pressure. LMA: laryngeal mask airway. ICU: intensive care unit.

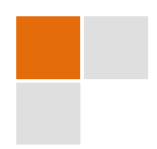




\section{Discussion}

In a parturient with Marfan syndrome, the progression of aortic dilation commonly occurs in the third trimester because of the hypervolemic and hyperdynamic state and hormonal effects on vasculature: inhibition of collagen and elastin deposition in the aorta wall $(9,10)$. The parturients with Marfan syndrome and an aortic root diameter of 40 $\mathrm{mm}$ or more are at increased risk of aortic dissection (1). Because our patient had significant aortic enlargement, Cesarean section was more reasonable than vaginal delivery to avoid an increases in cardiac output $(11,12)$.

Before general anesthesia was chosen for this patient, neuraxial anesthesia was also considered. However, the possibility of dural ectasia $(13,14)$ and the increased amount of cerebrospinal fluid (CSF) volume may restrict the spread of intrathecally-injected anesthetics and lead to inadequate spinal anesthesia (15). In addition, neuraxial anesthesia may be technically difficult for a possibility of skeletal system abnormality (3). Although there was a case for successful management using epidural anesthesia in a patient with Marfan syndrome (16), the use of epidural anesthesia in Marfan syndrome with moderate-to-severe dural ectasia is not recommended because of the risk of a spinal CSF leak due to accidental dural puncture (17). Also, it was difficult to apply epidural anesthesia for emergent Cesarean section in our patient with labor pain because of possibilities of the technical difficulty and the relatively longer time to achieve adequate anesthesia than spinal or general anesthesia.

Compared to neuraxial anesthesia, disadvantages of general anesthesia include excessive cardiovascular response followed by tracheal intubation. To minimize this cardiovascular response, we used an LMA instead of an endotracheal tube (7). Although the use of LMA for Cesarean section on the parturients with Marfan syndrome has been not yet reported, a successful use of LMA on a child with Marfan syndrome has been performed (18). The use of LMA should be prudent in a parturient woman undergoing Cesarean section considering the potential risk of aspiration of gastric contents. We noticed the 2 observational studies which revealed that the LMA was an effective and probably safe alternative to tracheal intubation for Cesarean section in 1067 and 700 healthy, non-obese parturients, respectively $(19,20)$. In addition, our patient fasted for $8 \mathrm{~h}$ and received antacid prophylaxis. Taken together, we decided to use a LMA in this case. Consequently, the LMA insertion provided effective ventilation and stable hemodynamics for our patient without any respiratory complications including aspiration.

Another important option for preventing elevation of BP in this case is the administration of opioids before delivery (4). Two case-reports have shown the successful use of fentanyl in general anesthesia for Cesarean delivery in parturients with Marfan syndrome $(14,21)$. In our case, we used remifentanil with rapid onset and offset of action instead of fentanyl before the delivery. Remifentanil effectively attenuated hemodynamic and catecholamine response to tracheal intubation in undergoing Cesarean delivery without severe neonatal respiratory depression (22). It also has a beneficial effect on the neonatal acid-base status (22). Richa et al. (23) reported that the use of remifentanil (loading dose $1 \mu \mathrm{g} / \mathrm{kg} / \mathrm{min}$ for $1 \mathrm{~min}$, maintenance dose $0.1-0.4 \mu \mathrm{g} / \mathrm{kg} / \mathrm{min}$ ) for Cesarean section in a parturient woman with HELLP (Hemolysis, Elevated Liver enzymes and a Low Platelet count) syndrome resulted in no respiratory depression in the neonate. In this 
case, we used the minimal dose based on their report and the newborn baby showed no neonatal depression.

It is known that beta-blocker such as landiolol (24) or calcium channel blocker such as nicardipine $(4,25)$ are also effective on hemodynamic management of the patients with Marfan syndrome during Cesarean section. We prepared those antihypertensive drugs. We also prepared ephedrine and epinephrine considering the possibilities of adverse events including hypotension or especially marked bradycardia which should be avoided in the patients with severe aortic regurgitation. Nevertheless, in our case, the use of remifentanil and LMA was sufficient to maintain maternal hemodynamic stability without cardiac drug requirement.

In conclusion, the use of remifentanil (loading dose of $1 \mu \mathrm{g} / \mathrm{kg}$ for $1 \mathrm{~min}, 2 \mathrm{~min}$ before induction; thereafter continuous infusion dose of $0.1 \mu \mathrm{g} / \mathrm{kg} / \mathrm{min}$ ) and LMA during general anesthesia for Cesarean section in a parturient woman with Marfan syndrome complicated by ascending aortic aneurysm can be useful to maintain maternal hemodynamic stability without neonatal respiratory depression.

\section{References}

1. Ho NC, Tran JR, Bektas A. Marfan's syndrome. Lancet. 2005;366:1978-81.

2. Meijboom LJ, Vos FE, Timmermans J, Boers GH, Zwinderman AH, Mulder BJ. Pregnancy and aortic root growth in the Marfan syndrome: a prospective study. Eur Heart J. 2005;26:914-20.

3. Pyeritz RE. The Marfan syndrome. Annu Rev Med. 2000;51:481-510.

4. Allyn J, Guglielminotti J, Omnes S, Guezouli L, Egan M, Jondeau G, Longrois D, Montravers P. Marfan's syndrome during pregnancy: anesthetic management of delivery in 16 consecutive patients. Anesth Analg 2013;116:392-8.

5. Myre K, Raeder J, Rostrup M, Buanes T, Stokland O. Catecholamine release during laparoscopic fundoplication with high and low doses of remifentanil. Acta Anaesthesiol Scand. 2003;47:267-73.

6. Schwarz GL, Volmanen P, Albrechtsen S, Bjoernestad E. Remifentanil target-controlled infusion during second stage labour in high-risk parturients: a case series. Acta Anaesthesiol Scand. 2013;57:802-8.

7. Ismail SA, Bisher NA, Kandil HW, Mowafi HA, Atawia HA. Intraocular pressure and haemodynamic responses to insertion of the i-gel, laryngeal mask airway or endotracheal tube. Eur J Anaesthesiol. 2011;28:443-8.

8. Kwak HJ, Chae YJ, Lee KC, Kim JY. Target-controlled infusion of remifentanil for laryngeal mask airway insertion during sevoflurane induction in adults. J Int Med Res. 2012;40:1476-82.

9. Meijboom LJ, Vos FE, Timmermans J, Boers GH, Zwinderman AH, Mulder BJ. Pregnancy and aortic root growth in the Marfan syndrome: a prospective study. Eur Heart J. 2005;26:914-20.

10. Manalo-Estrella $P$, Barker AE. Histopathologic findings in human aortic media associated with pregnancy. Arch Pathol. 1967;83:336-41.

11. Lipscomb KJ, Smith JC, Clarke B, Donnai P, Harris R. Outcome of pregnancy in women with Marfan's syndrome. Br J Obstet Gynaecol. 1997;104:201-6.

12. Hiratzka LF, Bakris GL, Beckman JA, Bersin RM, Carr VF, Casey DE Jr, Eagle KA, Hermann LK, Isselbacher EM, Kazerooni EA, Kouchoukos NT, Lytle BW, Milewicz DM, Reich DL, Sen S, Shinn JA, Svensson LG, Williams DM. 2010 CCF/AHA/AATS/ACR/ASA/SCA/SCAI/SIR/STS/SVM Guidelines for the diagnosis and management of patients with thoracic aortic disease: Executive summary: A report of the American College of Cardiology Foundation/American Heart Association Task Force on Practice Guidelines, American Association for Thoracic Surgery, American College of Radiology, American Stroke Association, Society of Cardiovascular Anesthesiologists, Society for Cardiovascular Angiography and Interventions, Society of Interventional Radiology, Society of Thoracic Surgeons, and Society for Vascular Medicine. Anesth Analg. 2010;111:279-315.

13. Foran JR, Pyeritz RE, Dietz HC, Sponseller PD. Characterization of the symptoms associated with dural ectasia in the Marfan patient. Am J Med Genet A. 2005;134A:58-65.

14. Lacassie HJ, Millar S, Leithe LG, Muir HA, Montaña R, Poblete A, Habib AS. Dural ectasia: a likely cause of inadequate spinal anaesthesia in two parturients with Marfan's syndrome. Br J Anaesth. 2005;94:500-4. 
15. Fettes PD, Jansson JR, Wildsmith JA. Failed spinal anaesthesia: mechanisms, management, and prevention. Br J Anaesth. 2009;102:739-48.

16. Kim G, Ko JS, Choi DH. Epidural anesthesia for cesarean section in a patient with Marfan syndrome and dural ectasia -A case report. Korean J Anesthesiol. 2011;60:214-6.

17. Buser RT, Mordecai MM, Brull SJ. Combined spinal-epidural analgesia for labor in a patient with Marfan's syndrome. Int J Obstet Anesth. 2007;16:274-6.

18. Ornek D, Aydin GB, Kahveci K, Cicek F, Dikmen B. Anesthetic management of a child with both Marfan syndrome and Turner syndrome. J Anesth. 2012;26:442-4.

19. Han TH, Brimacombe J, Lee EJ, Yang HS. The laryngeal mask airway is effective (and probably safe) in selected healthy parturients for elective Cesarean section: a prospective study of 1067 cases. Can J Anaesth. 2001;48:111721.

20. Yao WY, Li SY, Sng BL, Lim Y, Sia AT. The LMA Supreme in 700 parturients undergoing Cesarean delivery: an observational study. Can J Anaesth. 2012;59:648-54.

21. Ioscovich A, Elstein D. Images in anesthesia: Transesophageal echocardiography during Cesarean section in a Marfan's patient with aortic dissection. Can J Anaesth. 2005;52:737-8.

22. Heesen M, Klöhr S, Hofmann T, Rossaint R, Devroe S, Straube S, Van de Velde M. Maternal and foetal effects of remifentanil for general anaesthesia in parturients undergoing caesarean section: a systematic review and metaanalysis. Acta Anaesthesiol Scand. 2013;57:29-36.

23. Richa F, Yazigi A, Nasser E, Dagher C, Antakly MC. General anesthesia with remifentanil for Cesarean section in a patient with HELLP syndrome. Acta Anaesthesiol Scand. 2005;49:418-20.

24. Saeki N, Taguchi S, Kawamoto M. Successful management of a patient with Marfan syndrome complicated with acute aortic dissection using landiolol during Cesarean section. J Anesth. 2010;24:277-9.

25. Chang CY, Yang JM, Lam CW, Chen PH. Successful management of aortic dissection in a patient with Marfan syndrome during pregnancy. Am J Obstet Gynecol. 2013;208:e3-6. 